\title{
Kernos
}

Revue internationale et pluridisciplinaire de religion grecque antique

9 | 1996

Varia

\section{María Cruz HERRERo Ingelmo, Pausanias. Descripción de Grecia, Introducción, traducción y notas}

\section{Angel Ruiz Pérez}

\section{OpenEdition \\ Journals}

\section{Édition électronique}

URL : http://journals.openedition.org/kernos/1199

DOI : 10.4000/kernos. 1199

ISSN : 2034-7871

\section{Éditeur}

Centre international d'étude de la religion grecque antique

Édition imprimée

Date de publication : 1 janvier 1996

ISSN : 0776-3824

\section{Référence électronique}

Angel Ruiz Pérez, « María Cruz herrero ingelmo, Pausanias. Descripción de Grecia, Introducción, traducción y notas », Kernos [En ligne], 9 | 1996, mis en ligne le 21 avril 2011, consulté le 22 septembre 2020. URL : http://journals.openedition.org/kernos/1199 ; DOI : https://doi.org/10.4000/kernos.1199 
même titre que Vesta, qui a les mêmes origines troyennes que le Prince ${ }^{3}$. Quoi qu'il en soit, que Vesta ait revêtu une grande importance aux yeux d'Auguste, sa mention dans les Res gestae $(21,2)$ le prouve. De plus, c'est à cette déesse qu'Auguste fit élever, en 12 av. J.-C., une statue sur le Palatin et ériger un autel au même endroit, sans aller toutefois jusqu'à lui faire construire un temple, comme on l'a maintes fois soutenu, qui eût été la réplique de celui du forum où était conservé le feu sacré.

Les idées nouvelles contenues dans ce livre n'emporteront certes pas l'adhésion de tous. Elles ne laisseront en tout cas personne indifférent. Parmi les points de vue qui me paraissent un peu trop hardis, il faut signaler l'idée qu'Auguste institua un rapport nouveau entre hommes et dieux. Cette manière de concevoir la religion est loin d'être une innovation propre au début du Principat. On la trouve, sous une forme un peu différente, il est vrai, dès la deuxième guerre punique, lorsque $P$. Cornélius Scipion l'Africain, proclamé imperator sur le champ même de bataille sans être magistrat -, reçut la protection de l'auctoritas de Jupiter Capitolin, qui lui accorde l'imperium. Et ce n'est pas un cas unique: Sylla est dit felix, favorisé par les dieux, Pompée, dit Magnus, est le protégé de Jupiter Maximus, et César, imperator et parens patriae, est assimilé à la vieille divinité Romulus-Quirinus, lien qui annonce son apothéose, réplique de celle de Romulus.

Ce travail, qui repose sur une connaissance approfondie des sources anciennes et de la bibliographie moderne, constitue une contribution de valeur à l'étude d'un phénomène complexe.

Bruno RocheTTE

(Université de Liège)

María Cruz Herrero Ingelmo, Pausanias. Descripción de Grecia, Introducción, traducción y notas, Madrid, Editorial Gredos, 1994, 12,5 x $19,5 \mathrm{~cm}$, vol. I, libros I-II, 358 p. +4 cartes; vol. II, libros III-VI, 435 p. +3 cartes; vol. III, libros VII-X, 529 p. + 4 cartes (Biblioteca Clásica Gredos, 196, 197, 198). ISBN : 84-249-1650-6.

La science de la Philologie Classique se développe au rhytme de la parution de nouvelles éditions, études, lexiques, dictionnaires, mais on ne doit pas en oublier pour autant la valeur des traductions, fondamentales en tant que courroie de transmission pour une société ignorant de plus en plus les langues et les cultures antiques.

En Espagne, des groupes très importants de spécialistes de la civilisation antique se sont développés, qui prétendent situer la culture classique dans son époque de splendeur, le Siècle d'Or espagnol. Dans cette atmosphère, on doit saluer le progrès fait par la maison d'édition Gredos : sa Biblioteca Clâsica compte déjà les deux cents volumes. Les introductions à chaque volume ont acquis un prestige mérité, constituant une sobre mise à jour des problèmes essentiels de chaque ouvrage. Il est donc naturel de donner à la connaissance de la communauté scientifique internationale cette collection, destinée fondamentalement à un public cultivé de langue espagnole, mais qui a aussi une certaine valeur pour les spécialistes en général. 
Dans le livre dont nous rendons compte ici, nous trouvons une nouvelle traduction de Pausanias, un auteur fondamental à plus d'un titre, pour la culture grecque et aussi sa religion; le prof. Herrero fait une remarquable introduction (p. 7-77), où elle examine des aspects fondamentaux : biographie de Pausanias, caractéristiques de son œuvre (structure, contenu, méthode, but du livre, sources et modèles litteraires, public visé), caractéristiques principales du genre périégétique, pensée politique et, ce qui nous intéresse surtout, croyances religieuses de l'auteur. L'étude se referme, comme c'est la norme de cette collection, sur une approche de la fortune de l'œuvre en Occident, et notamment en Espagne. Les problèmes de transmission textuelle, manuscrits, éditions et traductions, servent de conclusion à cette première partie.

Le texte utilisé pour la traduction est celui établi par M.H. Rocha Pereira dans la Bibliotheca Teubneriana, avec quelques corrections (p. 72-73). La traduction choisit la littéralité et s'accompagne de quelques notes explicatives, philologiques au sens large du terme.

Nous disposons ainsi d'une étude et d'une traduction qui doivent devenir des instruments indispensables pour la recherche sur Pausanias en Espagne et - nous l'espérons - ailleurs également.

Angel Ruiz Pérez

(Université de Valladolid)

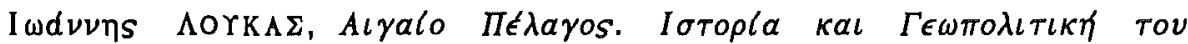

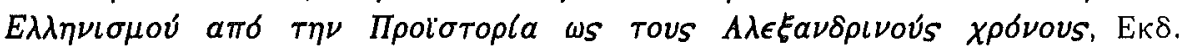

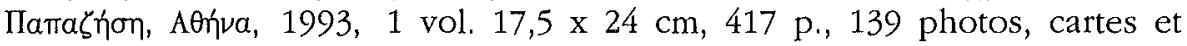
dessins.

L'A. entreprend, dans cette étude volumineuse, la tâche difficile de définir le rôle que la Mer Égée a pu jouer dans l'évolution historique et géopolitique de l'hellénisme, depuis ses débuts jusqu'à l'époque d'Alexandre. Pour parvenir à tisser une image globale, il rassemble des données aussi bien archéologiques, historiques, sociologiques, religieuses, politiques, que littéraires et philosophiques. Le fil conducteur est la juxtaposition, d'une part de la culture et de l'esprit helléniques, tournés depuis leur naissance vers la mer et, d'autre part, des civilisations asiatiques, fondées surtout sur l'étendue de leurs territoires. Une différence que l'A. qualifie de capitale, puisqu'elle comporte le noyau des éternels conflits entre les deux mondes, dans l'espace égéen (« Cas Oriental $)$.

Le premier chapitre étudie la période préhistorique ( De l'ère néolithique à la Guerre de Troie »), c'est-à-dire les civilisations cycladique, minoenne et mycénienne. Le deuxième chapitre reprend les éléments relatifs aux poèmes épiques d'Homère (où l'A. reconnaît dans le personnage du polymétis Ulysse la représentation symbolique des vertus d'un capitaine, helléniques par excellence), à "l'invasion » des Doriens et à la colonisation. Le troisième chapitre fait la liaison entre l'activité commerciale maritime et la fondation de l'« État rationnel », qui présente une structure politique centrée davantage sur l'individu (l'agora est désormais le centre de la cité). En même temps, la naissance de la philosophie dans les villes prospères de l'Asie Mineure marque une rupture avec la vision qu'offre la pensée « orientale » concernant l'homme et le monde. En complétant son identité, l'hellénisme joint à «Ulysse » le sage législateur et le philosophe. La démocratie, nourrie par l'économie 